\title{
As potencialidades turísticas e sua contribuição para o rural de Macaé-RJ
}

The tourist potentials and its contribution to the rural de Macaé-RJ

\section{Nelson José Zampier Bonin}

Universidade do Estado do Rio de Janeiro - UERJ - Rio de Janeiro - Rio de Janeiro - Brasil

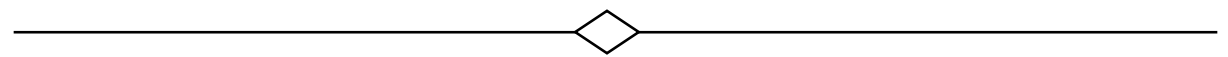

Resumo: Este artigo é resultado de um estudo exploratório sobre as potencialidades turísticas dos distritos da Região Serrana de Macaé, e seus benefícios para as comunidades rurais. Macaé é muito conhecida por ser a capital nacional do petróleo, mas não por abrigar belíssimas paisagens naturais em sua área serrana. O objetivo geral foi analisar as potencialidades turísticas dos distritos serranos e como o turismo pode ajudar na renda e manutenção da vida no campo. Foi utilizada uma breve pesquisa bibliográfica sobre 0 assunto, pois apenas encontramos trabalhos sobre 0 distrito do Sana, referente ao turismo. Então, foram realizadas visitas aos locais e levantamento de dados. Como resultado do trabalho, percebemos que existe um grande potencial turístico em toda a região, mas que ainda necessita de investimento em infraestrutura e de adaptação dos proprietários de terras para abrigar mais atrativos turísticos e protegê-los, mantendo o cotidiano de vida rural e produção rural, não apenas usufruindo simplesmente de cachoeiras e serras.

Palavras-chave: Turismo no meio rural. Potencialidades. Renda.

Abstract: This article is the result of an exploratory study about the tourist potentialities of the districts of the Mountainous Region of Macaé, and their benefits for the rural communities. Macaé is well known for being the national capital of oil, but not for harboring beautiful natural landscapes in its mountainous area. The general objective was to analyze the tourist potentialities of the mountainous districts and how tourism can help in the income and maintenance of rural life. We used a brief bibliographical research on the subject, since we only found works on the district of Sana, referring to tourism. Site visits and data collection were then carried out. As a result of the work, we realize that there is a great tourist potential in the entire region, but that still requires investment in infrastructure and adaptation of the landowners to shelter more tourist attractions and protect them, maintaining the daily life of rural life and production rural, not just enjoying waterfalls and saws.

Keywords: Tourism in the countryside. Potentialities. Income. 


\section{Introdução}

O município de Macaé situa-se na Mesorregião Norte Fluminense, a Nordeste do Estado do Rio de Janeiro e na Microrregião do mesmo nome. Segundo o IBGE (2010), contava com 206.748 habitantes e estimativa 2016 para 239.471 habitantes, sendo dividido em seis distritos (fig.1).

Figura 1 - Macaé e seus Distritos

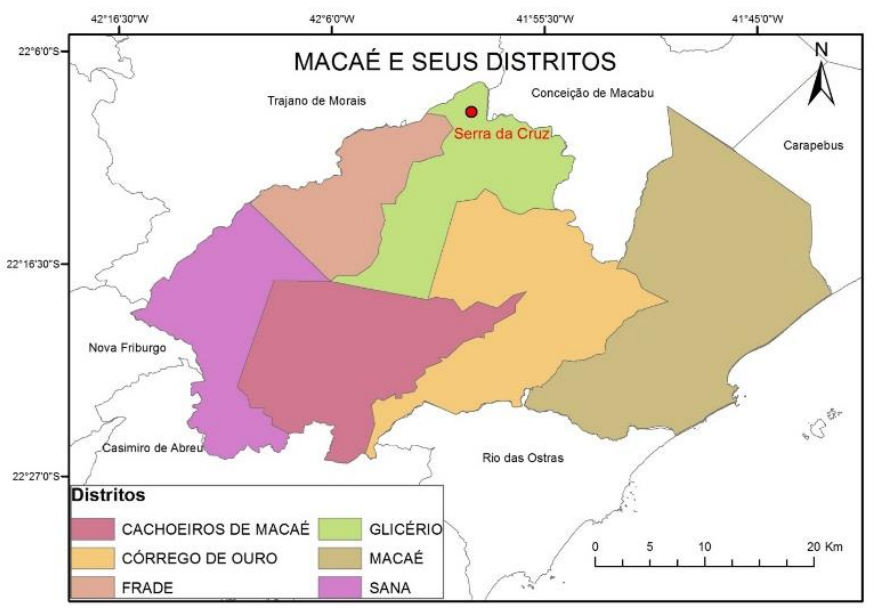

Fonte: $\mathrm{O}$ autor.

Em 1974, o futuro do Norte Fluminense ganhava novas perspectivas com a descoberta do petróleo na Plataforma Continental da Bacia de Campos, pois com a descoberta, a Petrobrás decide, ainda na década de 1970, instalar na cidade de Macaé, uma base terrestre de operações. Com isso, outras empresas particulares passam também a montar sedes na cidade, muitas das quais ligadas diretamente à atividade petrolífera. Os crescentes investimentos públicos e privados em infraestrutura, direcionado à atividade petrolífera, contribuíram para que a cidade, com características tipicamente rurais, cuja base econômica eram a pesca e a agropecuária, presenciasse profundas mudanças estruturais que alteraram radicalmente seu perfil econômico.

A partir do desenvolvimento econômico e aumento da empregabilidade, também ocorreu rápido crescimento populacional e mobilidade dessa população no território. Essas transformações influenciaram a dinâmica urbana, especialmente no distrito sede, mas também nos distritos de sua Região
Serrana. Como os investimentos da Petrobrás concentraram-se na área litorânea, os distritos da área serrana, baseados na agricultura e pecuária, não foram acompanhados por políticas públicas setoriais. Portanto, houve migração da área rural para os distritos, que deixaram de se basear nas atividades agrícolas, e a população passou a encontrar empregos mais atrativos na prefeitura, que teve seu quadro de empregados multiplicado muitas vezes, ou as pessoas passaram a trabalhar nas empresas offshore (embarcados), pois ganham mais. A falta de política agrícola e agrária em Macaé fez com que muitas propriedades deixassem a agricultura para se dedicar a pecuária de corte, menos onerosa. Assim, nossa pesquisa procura analisar as potencialidades turísticas da área serrana, para que não se perca as identidades culturais das populações locais, e que estas encontrem uma fonte de renda extra.

Analisamos o turismo como atividade complementar da renda na serra macaense, e também promovendo nova dinâmica nas relações campo-cidade. Nossa intenção é destacar a potencialidade turística dos distritos da região serrana de Macaé que ainda não estão aproveitando seus recursos naturais de forma que garanta renda $e$ melhor qualidade de vida para as pessoas que vivem no campo.

Relativo ao turismo de negócios ${ }^{1}$ e eventos, Macaé tem hoje a segunda melhor rede de pousadas e hotéis do Estado do rio de Janeiro, e a melhor do interior. O turismo de negócios corresponde a $71 \%$ do setor e a $10 \%$ do PIB do município (Prefeitura de Macaé, 2016). Devido à localização da base operacional da Petrobrás na cidade e ao conjunto de empresas offshore, existe grande movimentação de executivos e trabalhadores em geral, oficializando a porcentagem acima.

Rica em recursos naturais, Macaé está em uma situação geográfica privilegiada, abrigando serra e litoral dentro dos seus limites, o que atrai cada vez mais adeptos de esportes de aventura.

1 Turismo de Negócios \& Eventos compreende o conjunto de atividades turísticas decorrentes dos encontros de interesse profissional, associativo, institucional, de caráter comercial, promocional, técnico, científico e social (MINISTERIO DO TURISMO, 2010, p.15). 
Entre a Serra do Mar e o Oceano Atlântico, Macaé conta com interessantes formações geológicas, entre elas o ponto culminante do município, o Pico do Frade, com 1429m. Essa região é cortada por rios, cachoeiras e vales.

O município, para preservar suas riquezas naturais, criou cinco Áreas de Proteção Ambiental, além de possuir Reservas Particulares do Patrimônio Natural (RPPN) e duas Unidades de Conservação Federais, além de APPs (Área de Preservação Permanente) definidas por leis estaduais e federais.

No passado, a Serra Macaense produzia café nas encostas e arroz nas várzeas. Com a modernização da agricultura, o êxodo rural foi intenso, tanto para os distritos como para a Sede do município. Com a chegada da Petrobrás em 1978, as transformações intensificaram-se; a terra valorizou, a mão de obra encareceu, e as pessoas queriam trabalhar nas empresas offshore; mesmo com pouco estudo, procuram e muitas vezes encontram serviços de auxiliar de serviços gerais, cozinheiro ou outro tipo de serviço mais pesado. Então, muitos trabalhadores, apesar de viverem nos distritos, ou na própria zona rural, preferem trabalhar embarcado ou complementar a renda prestando serviços como pedreiro, jardineiro, pequenos comércios, motorista, etc.

Com a riqueza do Petróleo, o litoral ficou "inchado" em termos empresariais e populacionais, tornando a Serra um caminho para a diversão, paz, encontro com a família e amigos, etc.

O turismo chega como oportunidade de complementar à defasada renda proveniente do campo. Por mais que exista diferenciação conceitual entre órgãos de turismo dos diversos estados, regiões e até mesmo países, o conceito de turismo estabelecido pela Organização Mundial do Turismo (OMT), adotado oficialmente pelo Brasil, que compreende as atividades que as pessoas realizam durante viagens e estadas em lugares diferentes do seu entorno habitual, por um período inferior a um ano, com finalidade de lazer, negócios ou outras (Ministério do Turismo, 2006). Não é objetivo do trabalho aprofundar na discussão sobre o conceito de turismo, mas, sim, o que ele pode transformar estruturalmente e economicamente na área serrana de Macaé.

\section{Potencialidades turísticas da Região Serrana de Macaé}

Os tipos de turismo que exibem melhores oportunidades na área serrana são: o ecoturismo, o turismo rural e o turismo de aventura.

Segundo o Ministério do turismo (2010, p.17):

Ecoturismo é um segmento da atividade turística que utiliza, de forma sustentável, o patrimônio natural e cultural, incentiva sua conservação e busca a formação de uma consciência ambientalista através da interpretação do ambiente, promovendo o bem estar das populações.

Nessa perspectiva, Macaé possui boas possibilidades em suas áreas de preservação, mas isso ainda não é muito aproveitado.

Turismo Rural é o conjunto de atividades turísticas desenvolvidas no meio rural, comprometido com a produção agropecuária, agregando valor a produtos e serviços, resgatando e promovendo 0 patrimônio cultural e natural da comunidade (MINISTÉRIO DO TURISMO, 2010, p.18).

O turista quer presenciar o funcionamento do sítio ou fazenda, como ponto de atração. O problema é que essa visão ainda não foi totalmente enraizada pela população, que não investe no resgate da infraestrutura atrativa, como os engenhos, produção leiteira, reformas de casas antigas, etc.

Muitos autores, devido às variadas definições de turismo, preferem usar o termo "Turismo em áreas rurais", em contraposição a Turismo rural. CRUZ (2001) menciona que:

O turismo em espaço rural nada mais é que a apropriação, pelo turismo, de mais uma dimensão do espaço geográfico. (...) ao apropriar-se de espaços rurais, tais como de cidades e de áreas naturais, o turismo impõe sua lógica de uso desses espaços e a despeito dos conflitos que possam surgir desses processos, a prática turística promove, em geral, a reorganização desses espaços para que ela possa acontecer (p.20). 
Após muitos debates sobre conceituações de turismo em espaço rural, o Ministério do Turismo o define como:

Todas as atividades praticadas no meio não urbano, que consiste de atividades de lazer no meio rural em várias modalidades definidas com base na oferta: Turismo Rural, Turismo Ecológico ou Ecoturismo, Turismo de Aventura, Turismo de Negócios e Eventos, Turismo de Saúde, Turismo Cultural, Turismo Esportivo, atividades estas que se complementam ou não (MINISTÉRIO DO TURISMO, 2010, p.17).

De acordo com o Ministério do Turismo (2010), nota-se a abrangência que pode ter o termo turismo em espaço rural, englobando os aspectos econômicos, as riquezas naturais, a cultura, etc.

Para afirmar melhor o desenvolvimento de atividades turísticas em espaços rurais, Ribeiro e Marafon (2006) explicam que isso está ligado ao processo de urbanização decorrente de uma sociedade caracterizada pela assimilação do espaço rural pelo urbano.

Podemos perceber que as três práticas do turismo em áreas rurais são importantes na região serrana de Macaé, mas o turismo de aventura possui boa potencialidade nas localidades, além de ser bem diversificado. Turismo de Aventura compreende os movimentos turísticos decorrentes da prática de atividades de aventura de caráter recreativo e não competitivo (MINISTÉRIO DO TURISMO, 2010). É um tipo de turismo com grande potencial na Região Serrana, pelos seus atrativos: picos, cachoeiras, trilhas, etc.

Existe grande diversidade de práticas de turismo de aventura. $\mathrm{O}$ quadro 1 relata aquelas mais praticadas na região, segundo o Ministério do Turismo (2010):

\section{Quadro 1 - Principais práticas de turismo de aventura na Serra Macaense}

\begin{tabular}{|l|l|l|}
\hline Arvorismo: & Canoagem: & Parapente: voo \\
locomoção por & percurso aquaviário & de longa \\
percurso em & utilizando canoas, & distância com o \\
altura instalada & caiaques, ducks e & uso de aerofólio \\
em árvores e & remos. & (semelhante a \\
outras & & um pára quedas) \\
estruturas. & & impulsionado \\
& & pelo vento e \\
& & aberto durante \\
& & todo o percurso. \\
\hline
\end{tabular}

\begin{tabular}{|c|c|c|}
\hline $\begin{array}{l}\text { Atividades } \\
\text { Ciclísticas: } \\
\text { percurso em } \\
\text { vias } \\
\text { convencionais } \\
\text { e não } \\
\text { convencionais } \\
\text { em bicicletas, } \\
\text { também } \\
\text { denominado } \\
\text { de } \\
\text { cicloturismo. }\end{array}$ & $\begin{array}{l}\text { Rafting: descida em } \\
\text { corredeiras utilizando } \\
\text { botes infláveis. }\end{array}$ & $\begin{array}{l}\text { Caminhada: } \\
\text { percursos a pé } \\
\text { em itinerário } \\
\text { predefinido. } \\
\text { - curta duração: } \\
\text { caminhada de } \\
\text { um dia. } \\
\text { - longa duração: } \\
\text { caminhada de } \\
\text { mais de um dia, } \\
\text { também } \\
\text { chamada de } \\
\text { treking. }\end{array}$ \\
\hline \multirow{2}{*}{$\begin{array}{l}\text { Atividades } \\
\text { Fora de } \\
\text { Estrada: } \\
\text { percursos em } \\
\text { vias } \\
\text { convencionais, } \\
\text { com trechos de } \\
\text { difícil acesso, } \\
\text { em veículos } \\
\text { apropriados. } \\
\text { Também } \\
\text { denominado } \\
\text { turismo off } \\
\text { Road. }\end{array}$} & \multirow[t]{2}{*}{$\begin{array}{l}\text { Cachoeirismo: } \\
\text { descida em quedas } \\
\text { d'água utilizando } \\
\text { técnicas verticais, } \\
\text { seguindo ou não o } \\
\text { curso da água. }\end{array}$} & $\begin{array}{l}\text { Montanhismo: } \\
\text { caminhada, } \\
\text { escalada ou } \\
\text { ambos, praticada } \\
\text { em ambiente de } \\
\text { montanha. }\end{array}$ \\
\hline & & $\begin{array}{l}\text { Cavalgadas: } \\
\text { recursos em vias } \\
\text { convencionais e } \\
\text { não } \\
\text { convencionais, } \\
\text { em montaria, } \\
\text { também tratadas } \\
\text { de turismo } \\
\text { equestre. }\end{array}$ \\
\hline
\end{tabular}

Fonte: Ministério do Turismo (2010).

A Serra Macaense engloba os distritos de Cachoeiros de Macaé, Sana, Frade, Glicério e Córrego do Ouro, todos com determinadas potencialidades econômicas do turismo em áreas rurais, que serão abordadas neste texto.

O termo SANA possui várias versões, desde a denominação indígena local para um tipo de bambu; também pode ter derivado da ocupação suíça, lembrando o rio Sena, que corta a França; ganhou fama na década de 1970 por abrigar uma comunidade alternativa. Até hoje atrai muitos estudantes universitários, místicos e mochileiros em geral, que buscam locais mais calmos, com natureza, e longe da agitação urbana. É o distrito que possui a melhor infraestrutura para o turismo. Oferece um grande número de pequenas pousadas e restaurantes, além das áreas de campings. Na área do distrito encontra-se a APA do SANA, o que colabora para o processo de gestão.

Sua economia era vinculada à produção cafeeira, o que rendeu prosperidade ao local. 0 distrito abriga exuberante paisagem verde, o que acaba atraindo uma população basicamente urbana para a prática do ecoturismo. A partir de 1985, com a chegada da luz elétrica, o distrito do Sana passou a adquirir a função turística atual (SOUZA, 2009). Com 
isso, "ex-hippies" passaram a atuar nesse setor do turismo, pois os antigos hippies procuravam o Sana em busca de uma sociedade alternativa, longe do tumulto das cidades, próximo da natureza e se alimentando de produtos mais saudáveis. O distrito passou a produzir artesanatos e abrir pequenas pousadas, com isso reaquecendo a economia local. No verão, o fluxo de pessoas é intenso, e o excesso de visitantes é preocupante com relação ao meio ambiente e a comunidade local, com sobrecarga de lixo, esgoto, pisoteamento do solo e da vegetação, poluição dos rios e cachoeiras, com possibilidade de alterar o seu ecossistema.

Devido à riqueza natural, o Sana tem o ecoturismo e o turismo de aventura como principal fonte de renda (PAES, 2011). Muitas pousadas são administradas pelos neo-rurais, ou seja, pessoas da zona rural que foram para a cidade e retornaram com outras ideias. A população, em geral, ganha com o turismo, alugando casas, vendendo lotes, movimentando o comércio, como padarias, bares, restaurantes, inclusive caseiros, onde parte da produção rural é consumida. Muitos produtos artesanais são vendidos na feira do SANA, potencializando a renda de várias famílias. Percebemos, então, que o turismo em áreas rurais gera renda direta ou indireta aos produtores do distrito.

O trekking (fig.2) é praticado em dois lugares do SANA, o primeiro é no vale do Peito do Pombo, partindo do Arraial do Sana até o Peito do pombo, $1300 \mathrm{~m}$, com duração aproximada de 4 horas (PAES, 2011). O passeio é belíssimo, passando por cachoeiras, trilhas dentro da APA, etc. $O$ segundo lugar é o Pico do Frade, também partindo do arraial do Sana. Durante o percurso é possível aproveitar a exuberante biodiversidade da APA e, nos pontos mais elevados, avistar a bela paisagem.

\section{Figura 2 - Caminhada dentro da APA do Sana}

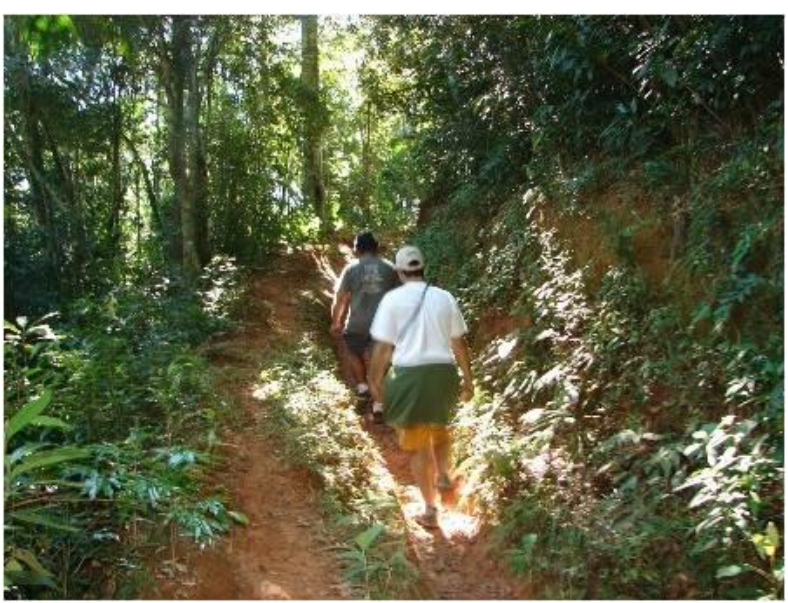

Fonte: Desema, 2014.

O rafting ( fig.3 ) e a canoagem são praticados na Barra do Sana, entre os rios Sana e Macaé, aproveitando as corredeiras com o desnível e maior volume d'água.

\section{Figura 3 - Raffting}

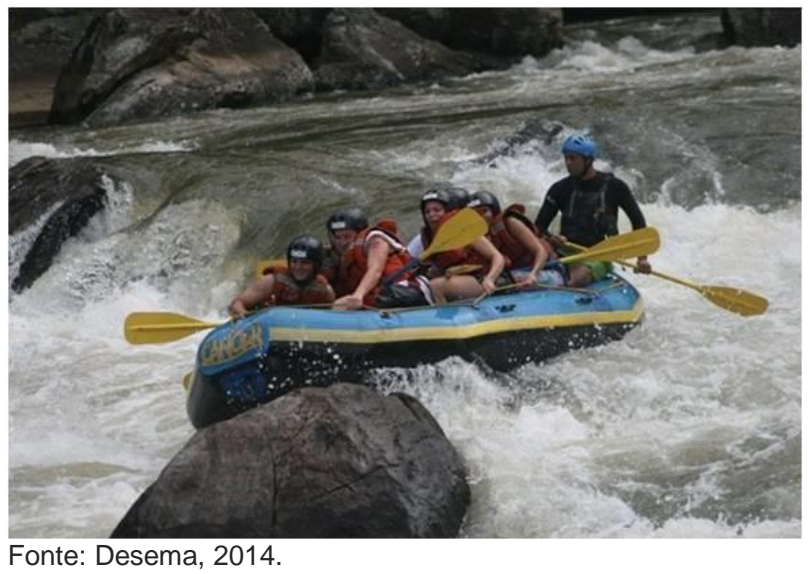

$\mathrm{Na}$ visita de campo realizada nesse distrito, seguimos o percurso da estrada Frade-Sana, com aproximadamente $21 \mathrm{Km}$ não pavimentados. Em conversa com alguns moradores, foi constatada falta de integração com a Sede Macaé e com os outros distritos da serra. O Sana está aproximadamente à $6 \mathrm{Km}$ da rodovia Serra-Mar, que liga Casimiro de Abreu à Friburgo, é asfaltada, fica a $16 \mathrm{Km}$ de Casimiro de Abreu e a mais de $70 \mathrm{Km}$ do centro do distrito sede de Macaé. Essa falta de integração é preocupante para o município, sendo que a população procura mais os municípios vizinhos para fazer compras em geral. Uma parcela da população é favorável ao asfaltamento do trecho entre Sana e 
Frade, mas outra parcela da população é contra, pois, segundo eles, haveria uma intensa urbanização e futura favelização. O crescimento urbano já ocorre na localidade ao longo da estrada. Em novembro de 2014, a Prefeitura de Macaé aprovou, junto à comunidade, o projeto de asfaltamento da estrada, porém não foi iniciada.

Já o Distrito do Frade sofreu transformações em sua extensão territorial, perdendo terras para criação do distrito de Glicério. Uma linha férrea ligava - Frade à Sede Macaé, mas, com a criação de Glicério, a linha passou a ligar Glicério-Macaé; isolando de certa forma o Frade. Isso acarretou certa estagnação econômica durante muito tempo. Apesar da prática do turismo, a renda principal vem da pecuária, agricultura e atualmente da realização de festas populares, também tradicionais na região. 0 distrito sofreu certa estagnação econômica, mas com o asfaltamento e recentemente com o subsídio do governo municipal, colocando a passagem a $R \$ 1,00$ em todo o município, vem colaborando para a atração populacional, pois a distância do centro ao Frade é de aproximadamente $50 \mathrm{~km}$; compensando morar nesse distrito e trabalhar em outros lugares. Seu principal atrativo turístico é o Pico do Frade e as cachoeiras. A fig.4 mostra a escalada do Pico do Frade.

\section{Figura 4 - Escalada do Pico do Frade (1429m)}

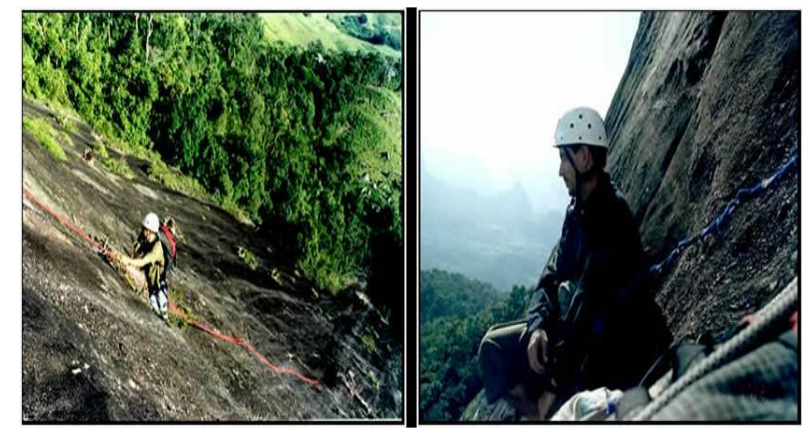

Fonte: Desema, 2014.

Glicério era uma localidade do distrito do Frade, por isso sua história está relacionada ao Frade. Glicério chamava-se Crubixais, de origem Tupi, que significa "rio de seixos", formado pelas corredeiras dos rios que cortam a região, formando uma paisagem ao longo de seu trecho, de pedras pilhadas. Crubixais passa a se chamar Glicério, em homenagem ao paulista General Glicério, então Ministro do Brasil.

Apenas na década de 1970, Glicério torna-se distrito. Atualmente sobrevive da pecuária, de algumas plantações de banana, e de um crescente potencial turístico.

Com o asfaltamento até o distrito, a infraestrutura melhorou, apesar de, nos trechos mais interiores, as estradas serem de terra batida, oferecendo um aspecto mais natural, como a estrada da Serra da Cruz, que sofre constante manutenção por parte da prefeitura, para a passagem de ônibus, escoamento da produção agrícola e fins turísticos.

A comunidade de Serra da Cruz é um exemplo de atrativo. Para chegar a esse local, quem vem de Macaé (sede), deve seguir a Rodovia RJ 168 até Trapiche, uma localidade urbana do distrito de Glicério, depois continuar por estrada não pavimentada até a localidade rural de Serra da Cruz. Ônibus coletivo percorre todo o trajeto. O festival do aipim ocorre no mês de julho, aproximadamente há 19 anos, onde moradores e comerciantes comemoram a colheita do aipim. A festa tem o apoio da secretaria de agroeconomia, EMATER-RJ e no passado, até da Petrobrás em determinados anos. Essa festa movimenta a região, sendo tradicional. Para isso a localidade conta com um Hotel Fazenda e casas para alugar.

Glicério oferece hotéis fazendas e diversas modalidades de turismo de aventura, como a canoagem e as cachoeiras (fig.5).

Figura 5 - Canoagem do tipo duck, em Glicério

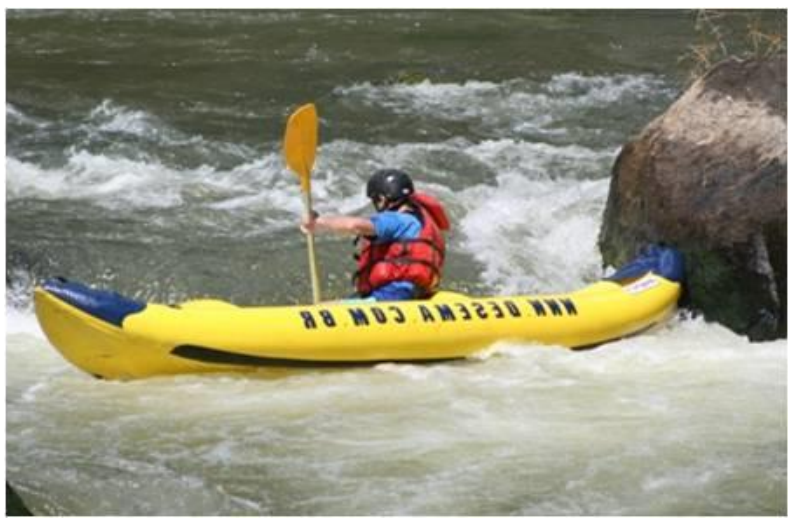

Fonte: Desema, 2014. 
O parapente (fig.6) também é bem praticado, possibilitando ao praticante vislumbrar uma paisagem exuberante.

\section{Figura 6 - Voo próximo a Glicério}

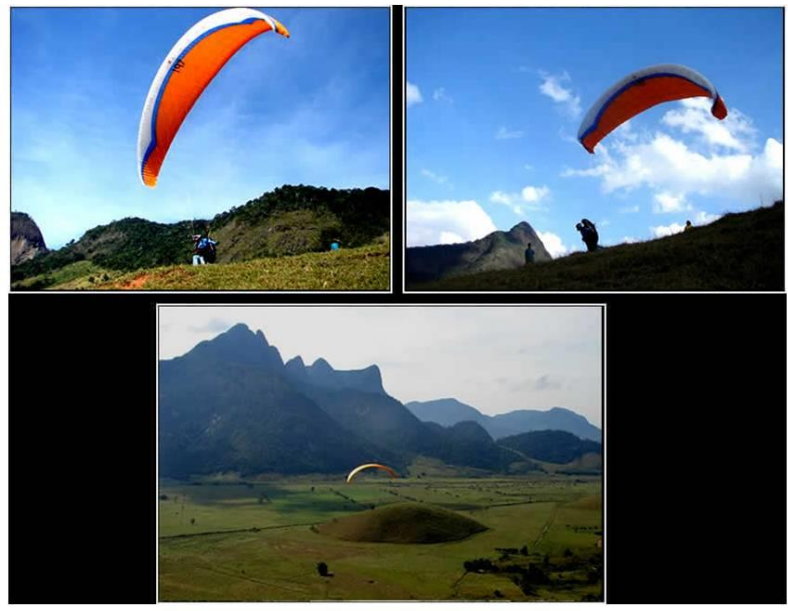

Fonte: Desema, 2014.

O turismo de aventura torna-se lucrativo na medida em que são consumidos vários itens de segurança, equipamentos e cursos. Os turistas consomem parte da produção agropecuária como os queijos, aipim, feijão, doces artesanais, que são produzidos pela população, tanto urbana, quanto rural. Algumas pessoas fazem de suas casas verdadeiras pousadas; abrem pequenos bares para atender os visitantes, etc. Por todos esses atrativos, algumas pessoas alugam casas para temporada na zona rural do distrito.

O Distrito de Cachoeiros de Macaé, na década de 1920, era líder municipal na produção de café, milho, arroz, feijão, etc. Por tudo isso, possuía o maior número de propriedades rurais e população. Com a crise de 1929 e a crise do café, o distrito perdeu a força e boa parcela da população.

Atualmente é o distrito menos populoso, concentrando sua economia na pecuária, principalmente e, em algumas lavouras. Algumas fazendas antigas, do café e do açúcar (em ruínas), as cachoeiras (fig.7) e o Parque do Atalaia, propiciam atrativos para o turismo histórico e ecoturismo.
Figura 7 - Cachoeira da Bicuda Grande

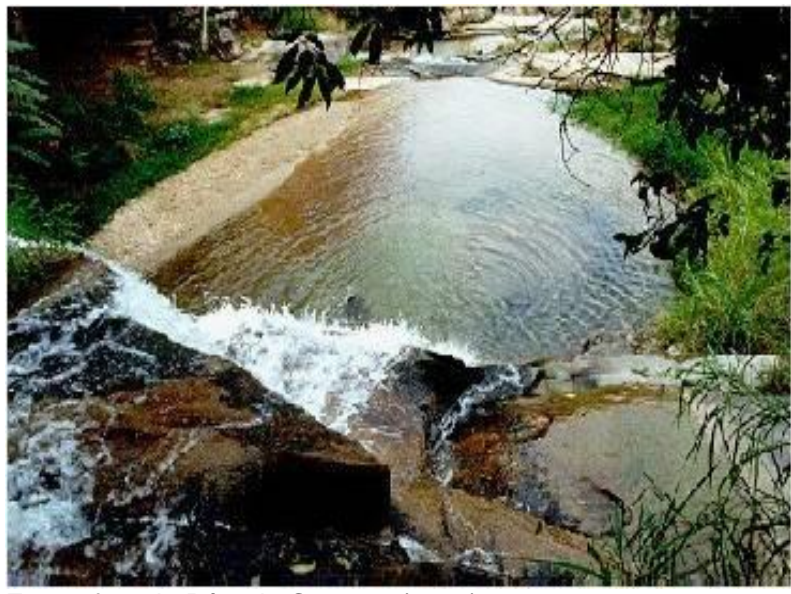

Fonte: foto de Rômulo Campos (2012).

O distrito de Cachoeiros de Macaé ainda possui atrativos históricos, datando os séculos XVII a XIX, como ruínas de cemitérios e outras construções antigas (fig.8 e fig.9).

\section{Figura 8 - Ponte-prisão, na Bicuda Pequena}

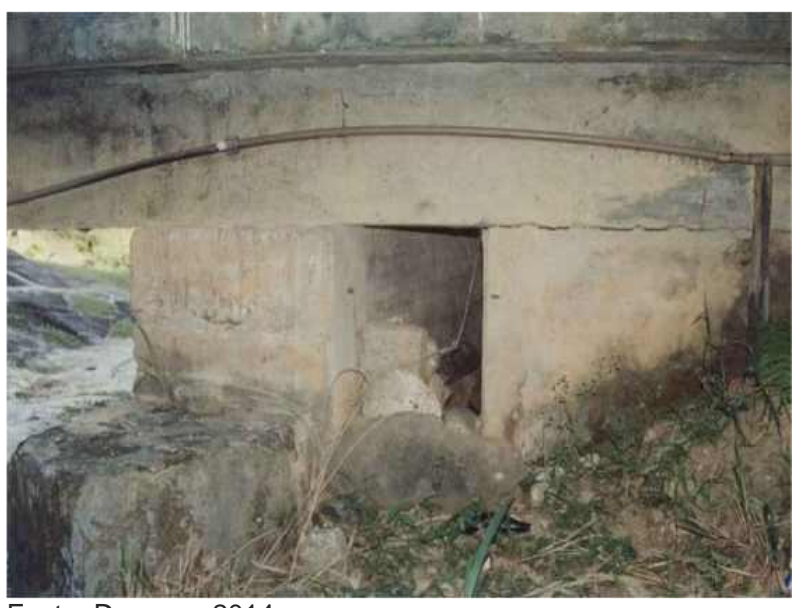

Fonte: Desema, 2014

Figura 9 - Casa do "Delegado da Bicuda"

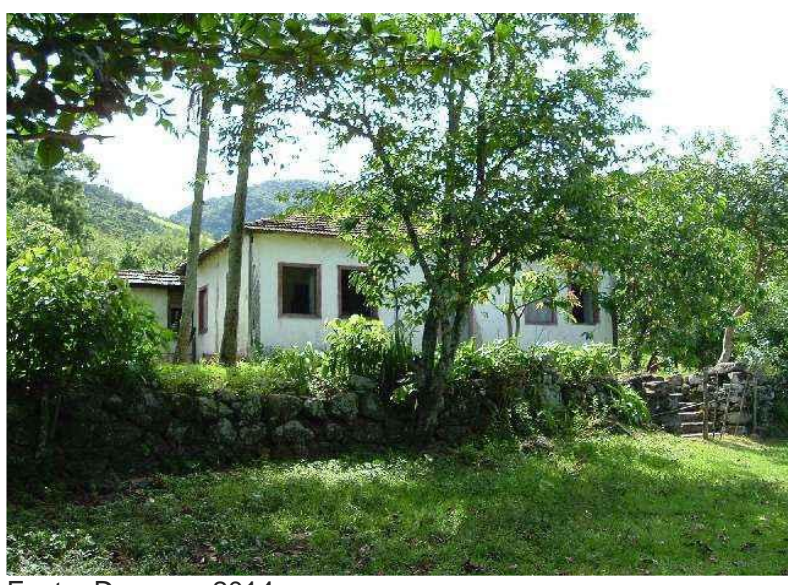

Fonte: Desema, 2014. 
Muitas construções, como os cemitérios, encontram-se deterioradas pelo tempo e vandalismo. O turismo em áreas rurais nesse distrito tem grandes possibilidades, pois ainda existe o atrativo histórico, as matas preservadas e suas belas cachoeiras, além da produção rural, que preserva o tradicionalismo da comida, cultura e modos de vida de um tempo passado. O mapeamento dos pontos de atração turística ainda necessita de reajustes, pois através do levantamento dos atrativos, pode-se planejar melhor as ações, e os empresários investirem melhor na hospitalidade, sendo que neste distrito existem pouquíssimas pousadas.

O Distrito de Córrego do Ouro surgiu a partir da iniciativa do imigrante italiano Pedro Adami, que cedeu lotes de sua fazenda para formar o povoado inicial. Atualmente é o distrito mais populoso e, por ser o mais próximo e de melhor acesso ao centro de Macaé, é o que mais cresce. É o único que possui banco, agência Itaú, maior número de instituições de ensino e o maior número de comerciantes, atendendo inclusive os distritos no seu entorno.

Não possui tantos atrativos turísticos como nos outros distritos; o mais atraente está no Parque Atalaia (fig.10), com a cachoeira do Salto, e também é utilizado para pesquisas e caminhadas ecológicas, principalmente.

Figura 10 - Caminhada no Parque Atalaia

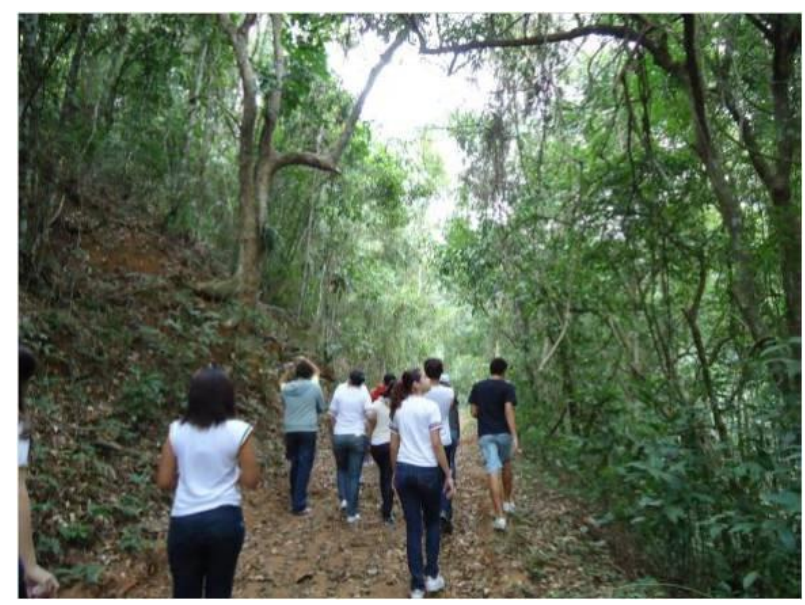

Fonte: Desema, 2014.

Instituições de ensino da prefeitura e outros colégios organizam visitas ao Parque Atalaia, onde são recepcionados pelos pesquisadores, que explicam aos alunos a importância da preservação ambiental e a biodiversidade da Mata Atlântica. O distrito, com mais de 4 mil Habitantes, conta com apenas duas pousadas. Através de conversas com os populares, foi constatado que, além de investimento em infraestrutura turística em termos de hospitalidade na região serrana de Macaé, falta carisma por parte de quem trabalha no ramo turístico, atraindo mais as pessoas a voltarem, ou permanecerem por mais tempo, vendendo uma imagem melhor do lugar.

\section{Considerações finais}

Procuramos realçar neste artigo, o que Macaé tem além do petróleo, discutindo as possibilidades turísticas e transformações no território rural a partir do turismo. Segundo nossos levantamentos, houve um "esquecimento" do campo, em termos de políticas públicas. Mesmo com potencialidade turística, a região serrana de Macaé, exceto partes do distrito do Sana e Glicério, não consegue organizar um plano que gere emprego e renda com o turismo, absorvendo mão de obra do campo.

O aumento do poder financeiro facilitou 0 investimento em asfaltamento e integração entre os distritos, exceto o Sana, intensificando a circulação de pessoas que, tanto moram na região serrana de Macaé e trabalham no distrito sede, como moram no distrito sede e buscam lazer e sossego nos distritos da serra macaense. O crescimento das atividades não agrícolas e pluriativas no meio rural ampliam as possibilidades de reprodução socioeconômica das pessoas, colaborando para que elas não saiam das suas localidades, ampliando a renda rural com a atividade turística. O crescimento da atividade turística nos distritos da serra macaense ou a sua possibilidade ainda dependem de um plano para a região. O plano mais avançado é o da APA do Sana, pois conta com o mecanismo de preservação e com crescente propaganda turística. Já os outros distritos ainda necessitam de mais infraestrutura e planejamento, além de propaganda. 


\section{Referências}

BRASIL, Ministério do Turismo. Segmentação do Turismo: Marcos Conceituais. Brasília: Ministério do Turismo, 2006.

BRASIL, Ministério do Turismo. Turismo de Aventura: Orientações Básicas. Brasília, 2010. 75p.

CRUZ, R. C. A. Introdução à Geografia do Turismo. São Paulo: Roca, 2001. 136 p.

DESEMA. Turismo de Aventura. Disponível em:<http:// http://www.desema.com.br/> Acesso em: 10 mar. 2017.

IBGE - INSTITUTO BRASILEIRO DE GEOGRAFIA E ESTATISTICA. SIDRA - Sistema IBGE de Recuperação Automática. Disponível em: www.ibge.gob.br Acesso em: fev de 2017.

Censo Demográfico 2010. Rio de Janeiro, 2016. Disponível em: www.ibge.gov.br. Acesso em: dez. de 2016.

Contagem da População 2016. Rio de Janeiro: IBGE, 2017. Disponível em: www.ibge.gov.br. Acesso em: jan. de 2017.

MACAÉ (RJ). Prefeitura. 2014. Disponível em: http://www.macae.rj.gov.br. Acesso em: fev. 2017.

PAES, Isaac Luis Lyrio. Turismo de Aventura: uma estratégia de combate à sazonalidade no município de Macaé-RJ. 2011. 49f.Monografia (Graduação em Turismo) -. Universidade Federal Fluminense, Quissamã, 2011.

RIBEIRO, M.A.; MARAFON, G. J. Agricultura Familiar, Pluriatividade e Turismo Rural: reflexões a partir do território fluminense. Campo - Território: revista de geografia agrária; Uberlândia, V.I, n.1, p.17 - 60; 2006.

SOUZA, Rodrigo S. de. A (Re) valorização das paisagens naturais para a prática do turismo: uma análise do ecoturismo no distrito do SanaMacaé RJ. In: $V$ Encontro de grupos de pesquisas: "Agricultura, Desenvolvimento Regional e Transformações Socioespaciais". UFSM, 2009. 